\title{
Private costs of patients hospitalized with community-acquired pneumonia
}

\author{
Philip Jacobs DPhil CMA ${ }^{1}$, Thomas J Marrie $\mathrm{MD}^{2}$, Peter Calder $\mathrm{PhD}^{3}$
}

P Jacobs, TJ Marrie, P Calder. Private costs of patients hospitalized with community-acquired pneumonia. Can Respir J 2005;12(4):205-208.

BACKGROUND: Community-acquired pneumonia (CAP) is a condition which frequently requires hospitalization and consequently, can result in high costs. Little is known of the additional personal resources that are used by patients hospitalized for CAP.

OBJECTIVE: To measure the private costs for persons who were hospitalized with CAP for the 30 days after being admitted to hospital using a systematic method of measurement.

METHODS: Potential personal cost items were identified by nurses familiar with the treatment of CAP and categorized. Using telephone interviews in conjunction with the cost-identification framework, 60 patients from the Edmonton, Alberta area were surveyed for their private costs associated with CAP for 30 days after admission to hospital. RESULTS: Of the 60 patients surveyed, 49 were older than 65 years of age. The mean private cost was $\$ 505$, which amounted to $5.6 \%$ of the total societal costs of $\$ 8,970$. The distribution was skewed with a small number of patients that had high costs.

CONCLUSIONS: This method allows the determination of the societal costs for patients hospitalized with pneumonia, and the costs were not much greater than those to the health care system.

\section{Coûts privés supportés par les patients hospi- talisés pour une pneumonie extrahospitalière}

CONTEXTE : Les pneumonies extrahospitalières (PEH) nécessitent souvent un traitement en milieu hospitalier et, par conséquent, peuvent entraîner des coûts élevés. Toutefois, l'on dispose de peu de données sur les ressources personnelles supplémentaires utilisées par les patients hospitalisés pour une $\mathrm{PEH}$.

OBJECTIF : Mesurer les coûts privés supportés par les patients hospitalisés pour une PEH durant les 30 jours suivant leur admission à l'hôpital, et ce, à l'aide d'une méthode systématique de mesure.

MÉTHODE : Une liste d'activités personnelles, susceptibles d'entraîner des coûts a été dressée par des infirmières bien au fait du traitement de la $\mathrm{PEH}$, puis divisée en catégories. Des entrevues téléphoniques ont ensuite été menées à l'aide de la grille de coûts auprès de 60 patients de la région d'Edmonton sur les coûts privés associés à la PEH durant les 30 jours suivant leur admission à l'hôpital.

RÉSULTATS : Sur les 60 patients interrogés, 49 étaient âgés de plus de 65 ans. Le coût privé moyen a atteint 505 \$, ce qui représente 5,6 \% du coût total de 8970 \$, supporté par la société. La répartition a été faussée par un petit nombre de patients qui ont déclaré des coûts élevés.

CONCLUSION : La méthode a permis de déterminer les coûts supportés par la société chez les patients hospitalisés pour une PEH, et ces coûts n'étaient pas beaucoup plus élevés que ceux attribués au système de santé.

Key Words: Cost; Hospitalization; Pneumonia

Community-acquired pneumonia (CAP) has an incidence Uof 12 cases per 1000 per year, and is the most common cause of death from infectious disease in the United States $(1,2)$. It is ranked as the eighth most cited reason for receiving hospital care within the Edmonton, Alberta Capital Health Region. While most patients can be treated on an out-patient basis, those who are admitted to hospital account for a large proportion of the costs to the formal hospital system. These patients are the focus of the present study.

Palmer et al (3) reported that a proportion of the outpatient data on home care and lost productivity for these high-cost cases were missing. While there was some attempt to collect private cost data (4), the authors did not use a systematic methodology to identify and classify these costs (5) and thus, may have missed some cost items. Jacobs et al (4) studied private costs for chronically ill patients with AIDS by developing a systematic identification and classification methodology, and showed that the private costs reported in previous studies were highly skewed. The purpose of the present study was to assess the private, out-ofpocket and indirect costs to patients hospitalized with CAP and their caregivers using a similar approach.

\section{Ethics approval}

\section{PATIENTS AND METHODS}

The protocol for the project was approved by the University of Alberta Health Research Ethics Board in Edmonton, Alberta. Patients, while in hospital, gave informed, written consent to be interviewed. Their informed consent was asked for a second time when they were interviewed over the phone approximately one month after giving first consent.

\section{Patient selection}

Sixty consecutive patients were interviewed, and were drawn from four hospitals within the Capital Health Region of Edmonton. The study nurses were requested to interview all patients with pneumonia on their wards.

\section{Time frame}

The costs that were incurred during the 30 days after the initial hospitalization were determined. The time period of onset of pneumonia before hospitalization was difficult to calculate, particularly with patients who might have had associated illnesses. With appropriate intervention, most patients should have the major

${ }^{1}$ Department of Public Health Sciences; ${ }^{2}$ Faculty of Medicine; ${ }^{3}$ Department of Educational Psychology, University of Alberta, Edmonton, Alberta

Correspondence: Philip Jacobs, Institute of Health Economics, 1200 - 10405 Jasper Avenue, Edmonton, Alberta T5J 3N4.

Telephone 780-448-4881, fax 780-448-0018, e-mail pjacobs@ihe.ab.ca 
TABLE 1

Potential service list for persons with pneumonia

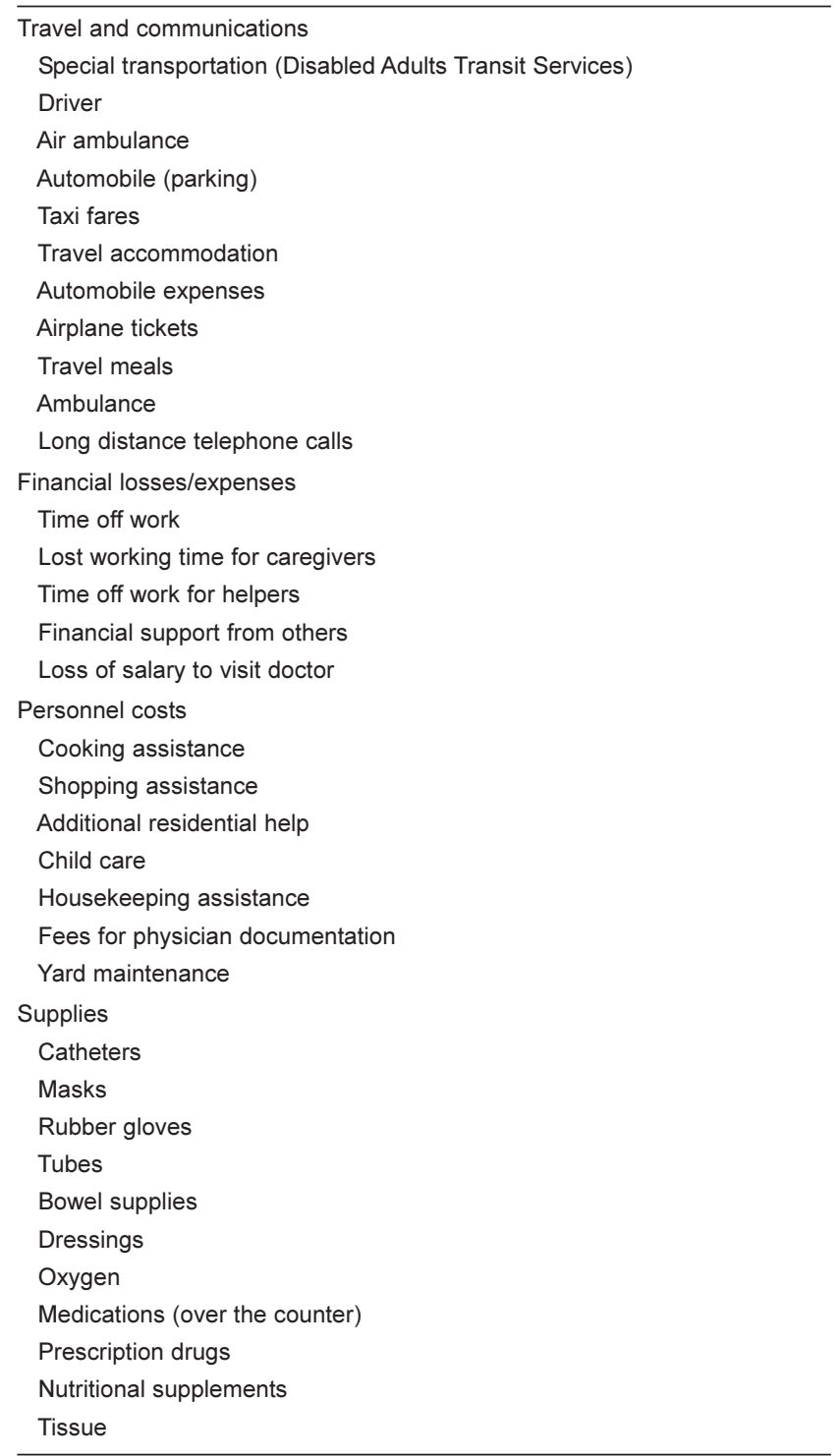

\section{Attributable costs}

In accounting for attributable costs, decisions had to be made as to which costs were to be allowed. Guidelines were developed to allow for acceptable cost items. Pneumonia-related costs that would pose an extra personal burden on the patient or their caregivers were focused on. The following variables were considered in arriving at the private out-of-pocket costs for each patient.

Private costs: A private cost was defined as one where there was an actual "out-of-pocket expenditure" or a loss of income that was borne by the patient or their caregiver, and was always related to resources. The cost of pain and suffering, loss of quality of life or some other situation in which there was no financial loss, and costs that were borne by the health care system, governments or insurance were not included. An ongoing cost that existed before the onset of CAP was excluded because it could not solely be attributed to CAP.

Caregiver costs: Costs generated by the primary caregiver (or the equivalent, if more than one person shared care) were included. These costs included travel expenses for the caregiver for hospital visits and for any time lost from work.

Standard unit costs: To ensure that the results reflected differences among patients in actual resources used (rather than the prices paid for them), where available, a standard list of costs was used to evaluate the dollar value of the resources used. The list of standard costs and data sources are shown in Table 2 .

\section{Initial cost list and structured interview}

The initial list of potential cost items was divided into four categories and formed the basis of the structured telephone interviews. Several types of cost items (eg, ground ambulance and prescription drugs) were frequently, but not always, covered by the government or private insurance. These items were placed into a separate group, and the costs were analyzed with and without this group. In addition to the cost items, patients were asked for basic demographic information. Patients or their caregivers were asked to add any additional costs that were not listed. Where patients incurred a cost, they were asked to report or estimate its cost. They were also asked if the cost was covered by a third party and if they had to pay a portion of the cost. In cases where standardized costs were used, they were not asked for the actual cost.

\section{RESULTS}

Basic sample characteristics are shown in Table 3. A total of 60 patients or their caregivers were interviewed. Thirtyeight patients and 22 caregivers (as patient proxies) were interviewed. Two additional patients who were telephoned were reported to be deceased and are not included in the summary statistics. Eight patients who had given informed consent to participate could not be reached after five attempts. The average age of the patients was approximately 70 years (range 39 to 95 years); 49 of the 60 patients were older than 65 years of age. The average stay in hospital was 11.63 days, with six of the 60 patients remaining in hospital longer than 30 days.

Because the majority of the patients were older than 65 years of age, in Alberta, they would automatically have Blue Cross drug coverage, which would also cover the majority of their added personal medical expenses. Some of the patients younger than 65 years of age had additional coverage or supplemental coverage to the basic Blue Cross plan. Only one of the 60 patients was without insurance. The patients had an average copayment of $19.3 \%$ on their health insurance, 
TABLE 2

Standard units used in the cost calculations

\begin{tabular}{|c|c|c|}
\hline Cost item & Unit cost (\$) & Source of data \\
\hline \multicolumn{3}{|l|}{ Travel and communications } \\
\hline Ground ambulance (per trip) & 700.00 & Edmonton emergency medical services \\
\hline Taxi (per two-way trip) & 20.00 & Edmonton taxi services \\
\hline Accommodations (per night) & 60.00 & Capital Health Authority cost for visitors \\
\hline Parking (per session) & 4.00 & \\
\hline Meal (at hospital) & 4.50 & \\
\hline Telephone, long distance (per minute) & 0.15 & Telus (Alberta), long distance rate per minute. \\
\hline Automobile expenses per km & 0.40 & Alberta Treasury guidelines (11) \\
\hline Automobile expenses per city trip & 8.00 & Assumed $10 \mathrm{~km}$ each way \\
\hline \multicolumn{3}{|l|}{ Financial } \\
\hline Loss of work (per day) & 125.00 & Statistics Canada (12), average daily wage per person over 50 years of age \\
\hline \multicolumn{3}{|l|}{ Personnel costs } \\
\hline Physician documentation fee & 25.00 & Fee per office visit, Alberta Health and Wellness (9) \\
\hline \multicolumn{3}{|l|}{ Other medical services } \\
\hline Medications (prescription) & 5.00 & Nominal cost per prescription \\
\hline
\end{tabular}

excluding the cost of ambulance service, which is fully covered in Alberta. Because most of the patients were older than 65 years of age, they were no longer employed and, hence, did not lose wages due to illness. Typically, their caregiver was their marriage partner who was also elderly and not employed, and also did not lose salary.

A summary of the private costs, including and excluding items that could potentially be subject to insurance coverage is shown in Table 4. Without ground ambulance and other medical expenses, the mean cost per person was $\$ 505 \pm 983$. The median was $\$ 138$. The relation between mean and median indicate that the distribution of private costs was skewed towards the right, with the highest value being $\$ 4,474$.

The items that most frequently appeared on the service list were taxi rides, parking, meals and long distance telephone calls. Most subjects incurred private transportation costs; the most frequently appearing was private automobile costs.

Ground ambulance costs were the most frequent costs in the other health groups. Of the 33 patients who arrived at hospital by ground ambulance, eight also required a second ambulance trip either because of a second admission or transfer to an auxiliary hospital. Approximately one-half of the patients incurred at least one ambulance ride, but all were covered by insurance.

\section{DISCUSSION AND CONCLUSIONS}

In the present paper, we developed a method to identify and categorize private costs for patients who had been hospitalized with CAP. Using this framework, we conducted personal interviews to measure their private costs for the 30 days following admission to hospital. Our results indicate that the average person incurred private costs of $\$ 505$ and that these were largely related to transport. The majority of the costs were for lost income (for those who were in the labour force) and for automobile travel.

To our knowledge, there have been no other studies that have examined the private costs of CAP. Several Canadian papers $(6-8)$ have reported the measures of private costs for other conditions, but they did not develop the measures using focus groups and systematic design methods; without these methods, one cannot be sure that the items for which the costs are obtained are complete.
TABLE 3

Subject characteristics $(n=60)$

\begin{tabular}{lc}
\hline Sex $(\mathrm{n})$ & \\
Male & 31 \\
Female & 29 \\
Age (years) & \\
Mean $\pm \mathrm{SD}$ & $69.78 \pm 14.08$ \\
$\quad$ Range & 39 to 95 \\
Number hospitalized & 60 \\
Average days in hospital $( \pm \mathrm{SD})$ & $11.63 \pm 8.55$ \\
Car trips & \\
$\quad$ Hospital trips by car & 57 \\
Average number of trips $( \pm \mathrm{SD})$ & $11.23 \pm 8.77$ \\
Ambulance trips & \\
$\quad$ Number of patients who made trips & 33 \\
Average number of trips $( \pm \mathrm{SD})$ & $1.21 \pm 0.42$ \\
\hline
\end{tabular}

The cost can be related to estimated medical costs for an episode of pneumonia, which includes an emergency room visit (9), along with a physician component (10) (\$294) and hospital stay of 11 days at $\$ 659$ per day (9) along with physician visits (\$451) (10) totalling $\$ 7,994$. To obtain total societal costs, we must add the private costs $(\$ 505)$ and the other insured health care costs, such as drugs and ambulance $(\$ 471)$; the total societal costs for hospitalized CAP cases were $\$ 8,970$. Thus, private costs amounted to $5.6 \%$ of the total. In large part, the low costs are due to the fact that most patients did not work.

Any definition of 'private costs' is dependent on the social environment in which the patient is treated. Social programs, medical care coverage and caregiver support will all have an influence on out-of-pocket costs. We separated drugs and ground ambulance because in Alberta they were covered for virtually all of the patients in our study, although in other provinces or jurisdictions this may not be the case. We also excluded air ambulance services because domestic air ambulance costs are publicly covered in the Canadian health care system. However, the degree of coverage depends on the circumstances. 
TABLE 4

Private costs by category

\begin{tabular}{|c|c|c|c|}
\hline $\begin{array}{l}\text { Costs not commonly covered } \\
\text { by provincial health plans }\end{array}$ & $\begin{array}{l}\text { Number of persons } \\
\text { who incurred costs }\end{array}$ & $\begin{array}{c}\text { Average } \pm \text { SD costs for } \\
\text { persons who incurred any costs (\$) }\end{array}$ & $\begin{array}{l}\text { Average cost for } \\
\text { all persons (\$) }\end{array}$ \\
\hline Parking & 54 & $42.00 \pm 32.00$ & 38.00 \\
\hline Taxi & 1 & 280.00 & 5.00 \\
\hline Out-of-town bus fares & 1 & 152.00 & 3.00 \\
\hline Accommodations & 1 & 60.00 & 1.00 \\
\hline \multicolumn{4}{|l|}{ Financial losses/expenses } \\
\hline Days off work & 12 & $1,619.00 \pm 1,244.00$ & 297.00 \\
\hline Caregivers loss of work & 4 & $625.00 \pm 318.00$ & 41.00 \\
\hline Salary loss to visiting doctor & 1 & 125.00 & 2.00 \\
\hline \multicolumn{4}{|l|}{ Personnel costs } \\
\hline Tissue & 55 & 1.00 & 1.00 \\
\hline Total \pm SD, excluding drugs and ground ambulance & & & $505.00 \pm 983.00$ \\
\hline \multicolumn{4}{|l|}{ Costs sometimes covered by provincial health plans } \\
\hline Ground ambulance & 33 & $848.00 \pm 290.00$ & 466.00 \\
\hline Prescription drugs & 60 & 5.00 & 5.00 \\
\hline Total $\pm S D$, including drugs and ground ambulance & & & $982.00 \pm 1,156.00$ \\
\hline
\end{tabular}

Three additional ambulance trips for patients in our sample involved transportation by air. All were covered by insurance.

We have included only time lost from work, not from leisure or other activities, as private costs. Time lost from leisure does have an opportunity cost, but this was both hard to identify and measure, and therefore, it was left out of the analysis.

Several shortcomings in the study method should be noted. First, although the nurses were asked to collect data for all persons who were hospitalized with pneumonia, it is likely that a number may have been missed. However, we could not discern which patients these were, and so we do not know if our sample was unbiased. Second, because of the difficulties in recruiting outpatients, we did not study the costs for patients with CAP who were not admitted. Obviously, such data would be of interest to policy makers because it would allow for the comparison of costs on a societal level of inpatients versus outpatients.

FUNDING: Support for this project was obtained from a grant from Bayer HealthCare Inc to the Institute of Health Economics at the University of Alberta. Dr Marrie has received support from the Alberta Heritage Foundation for Medical Research through an establishment grant. The Institute of Health Economics provided funding for the study.

ACKNOWLEDGEMENTS: We acknowledge the contribution of the research nurses, who helped with patient identification and data collection.

\section{REFERENCES}

1. Marrie TJ. Community-acquired pneumonia. Clin Infect Dis 1994;18:501-15.

2. Garibaldi RA. Epidemiology of community-acquired respiratory tract infections in adults. Incidence, etiology, and impact. Am J Med 1985;78:32-7.

3. Palmer CS, Zhan C, Elixhauser A, et al. Economic assessment of the community-acquired pneumonia intervention employing levofloxacin. Clin Ther 2000;22:250-64.

4. Jacobs P, Calder P, Houston S. The classification and measurement of private health-related costs. (Working paper 98-12). Edmonton: Institute of Health Economics, 1998.

5. Trochim W. Concept Mapping System Concept Systems. Ithica, Cornell Custom Publishing, 1998.

6. Browne G, Gafni A, Roberta J, Goldsmith A, Jamieson E. Approach to the measurement of costs (expenditures) when evaluating health and social programs. Paper 95-11. Hamilton: McMaster University, Systems Linked Research Unit, 1995.

7. Ungar WJ, Coyte PC; and the Pharmacy Medication Monitoring Program Advisory Board. Prospective study of the patient-level cost of asthma care in children. Pediatr Pulmonol 2001;32:101-8

8. Ungar WJ, Coyte PC. Measuring productivity loss days in asthma patients. The Pharmacy Medication Monitoring Program Advisory Board. Health Econ 2000;9:37-46.

9. Alberta Health and Wellness. Health costing in Alberta. 2002 Annual Report. Edmonton: Alberta Health and Wellness, 2002.

10. Alberta Health Care Insurance Plan. Schedule of Medical Benefits. Edmonton: Alberta Health and Wellness, 2001.

11. Personnel Administration Office, Alberta government. <www.pao.gov.ab.ca/benefits> (Version current at December 13, 2004).

12. Statistics Canada. Labour Survey, Edmonton Regional Office, 2003. 


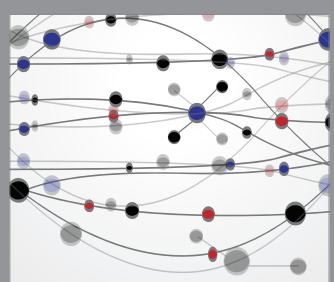

The Scientific World Journal
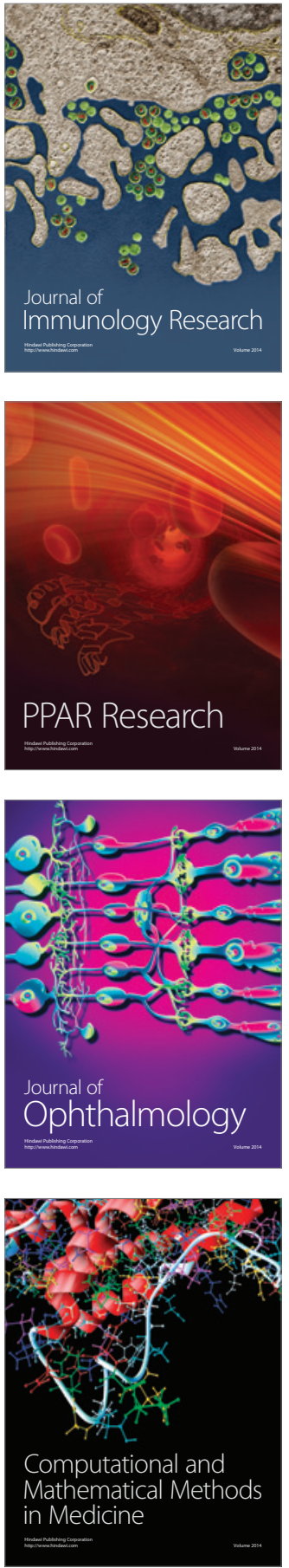

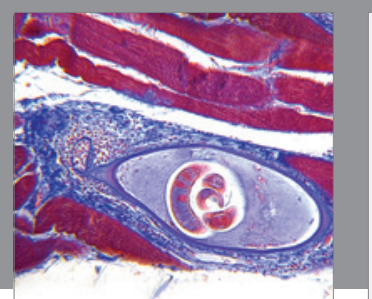

Gastroenterology Research and Practice

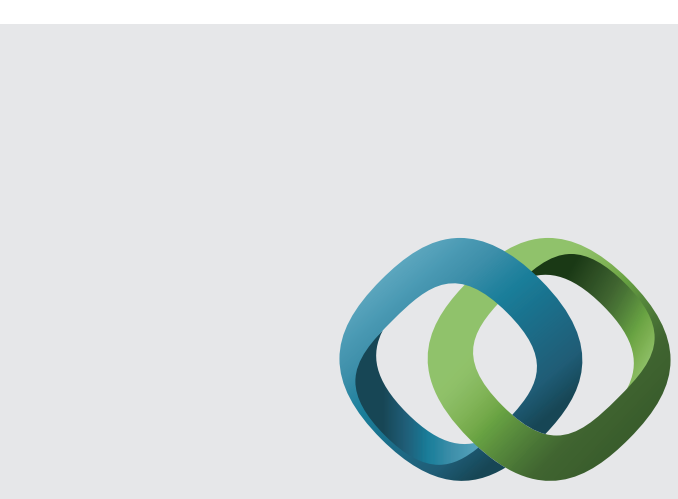

\section{Hindawi}

Submit your manuscripts at

http://www.hindawi.com
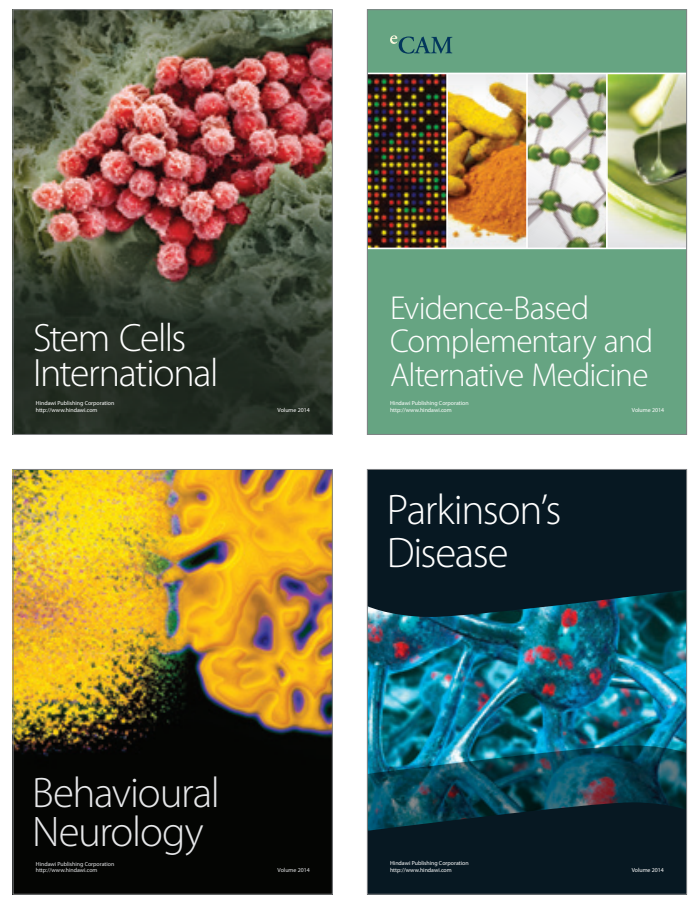
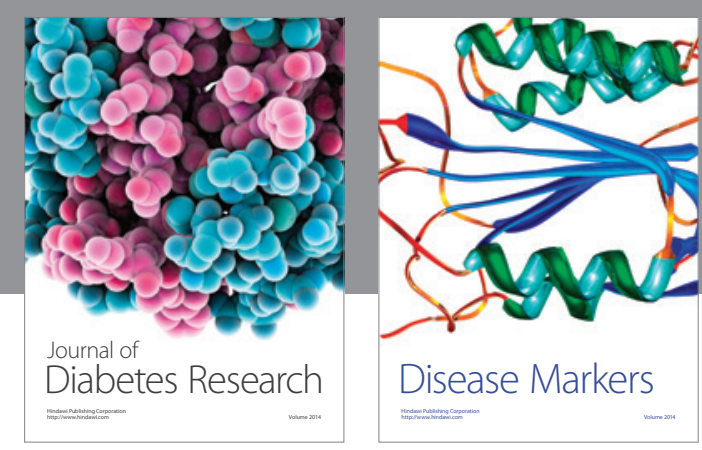

Disease Markers
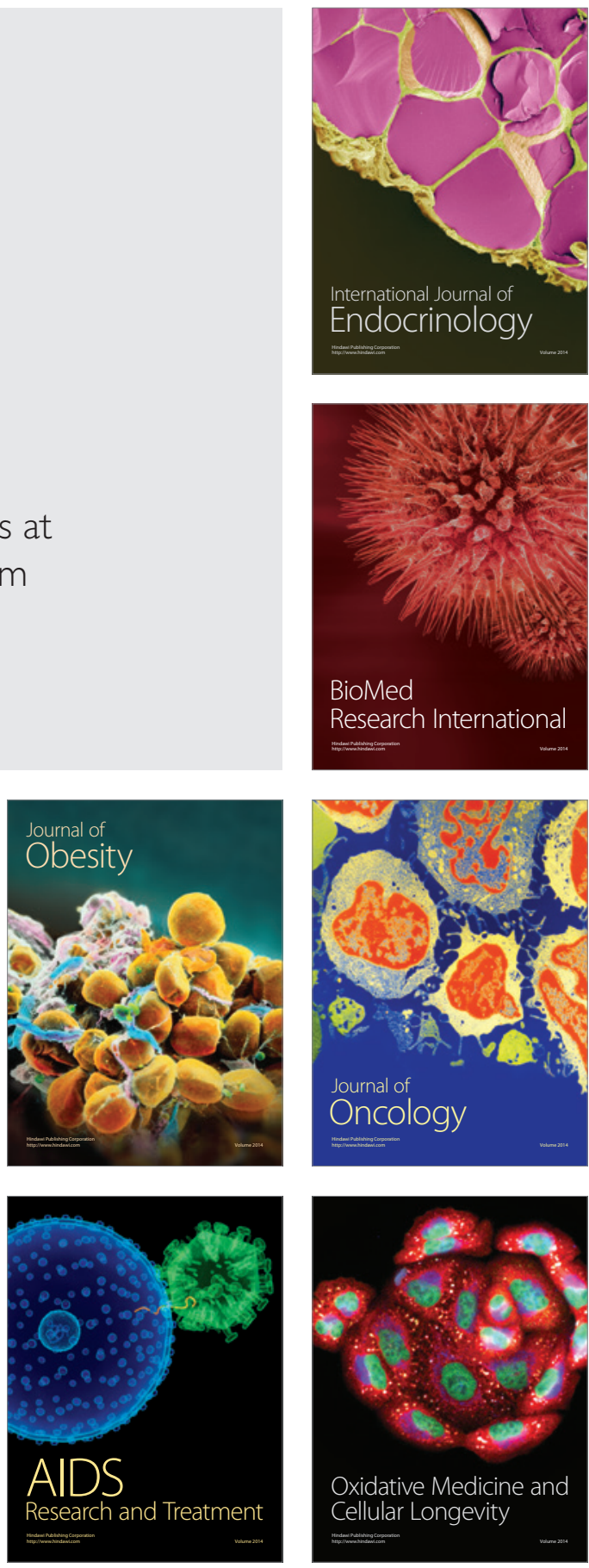